\title{
COMPOSIÇÃO GRAVIMÉTRICA DE RESÍDUOS SÓLIDOS URBANOS: ESTUDO DE CASO - MUNICÍPIO DE BOCAIÚVA - MG
}

Jéssica Cristina Lopes Oliveira - jessicalopesoliver1994@ gmail.com Faculdades Santo Agostinho

Eva Christina Santos Duarte - eva-christina26@ hotmail.com

Faculdades Santo Agostinho

Dalvana Pereira Santos - dalvanasantos123@gmail.com

Faculdades Santo Agostinho

Franciele Alves Santos - francielealvessantos@ hotmail.com

Faculdades Santo Agostinho

Thainá de Paula Cacique e Silva- thainakacique @ hotmail.com

Faculdades Santo Agostinho

Vitor Hugo Silva Veloso - vitorhugo_silvaveloso@ hotmail.com.br

Faculdades Santo Agostinho 


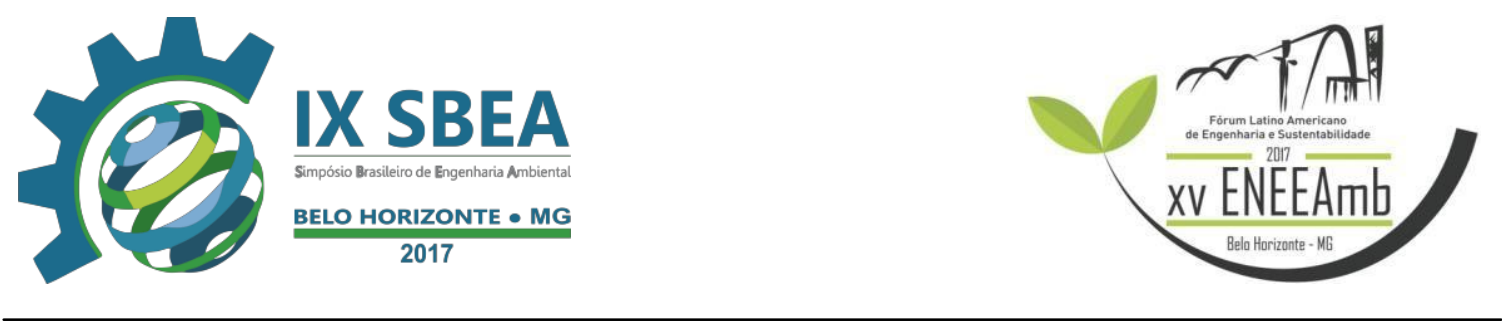

\section{RESUMO}

Resíduos sólidos são um aglomerado de itens gerados em diferentes gêneros, o qual não são mais úteis em atividades humanas, de competências domésticas, comerciais, industriais, de serviços e operações de varrição urbana, entre outros. O presente artigo foi desenvolvido com o intuito de estimar a geração de Resíduos Sólidos Urbanos (RSU) na cidade de Bocaiúva- MG de forma quantitativa e qualitativa com o objetivo de calcular a produção per capta e peso específico, podendo a partir de então realizar a avaliação da composição gravimétrica dos RSU do município, executado por meio de um estudo de caso. Para desenvolvimento do mesmo foi realizado uma visita ao Aterro Sanitário onde é destinado os RS do município, em seguida foram recolhidas amostras dos mesmos, e pesadas de forma geral e separadamente por categorias. Como resultado após a caracterização e composição gravimétrica dos RSU pôde se observar taxas significativas de material orgânico obtendo $40 \%$ dos RS coletados, e materiais recicláveis que somam $60 \%$ dos RS. O qual indica que o percentual de RS orgânico é consideravelmente elevado, podendo ser correspondente a maiores números de coletas realizadas em residências domésticas, ou por consumo elevado da população. Já o alto índice da categoria papel e plástico entre outros aspectos é provavelmente conseqüente do sucessivo crescimento urbano na cidade e o desenvolvimento econômico, no entanto a categoria dos metais não atingiu uma parcela significativa nas amostras coletadas. Portanto, o estudo gravimétrico é indispensável para a análise, implantação e manejo de toda e qualquer técnica visando o tratamento dos resíduos. Contudo, este trabalho apresenta a relevância da realização de estudos buscando alternativas para a elaboração e implantação de sistemas de compostagem de resíduos no município.

Palavras-chave: Resíduos sólidos, Composição gravimétrica e Aterro Sanitário.

\section{INTRODUÇÃO/OBJETIVO}

Resíduos sólidos são materiais, substâncias, objetos descartados derivado de atividades humanas em sociedade, a cuja destinação final se procede, se propõe proceder ou se está obrigado a proceder, nos estados sólido ou semissólido, bem como gases contidos em recipientes e líquidos cujas particularidades tornem inviável o seu 


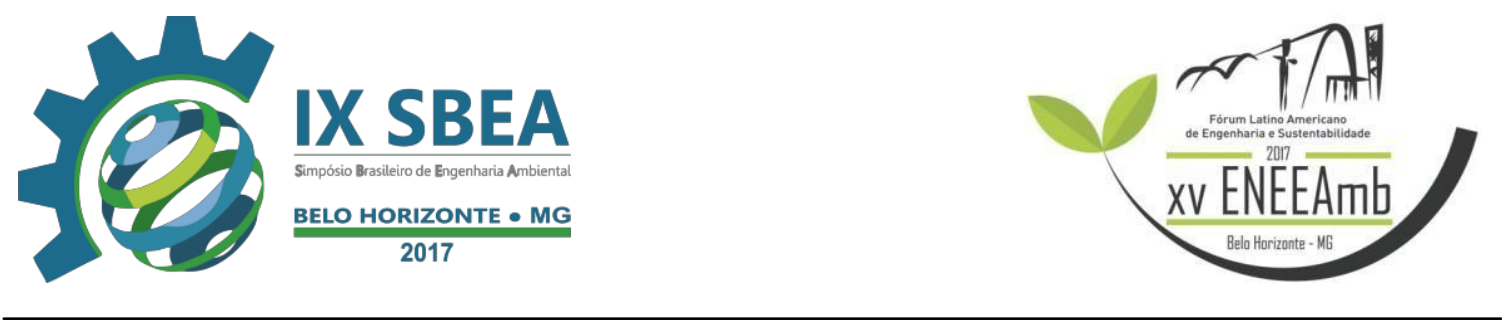

lançamento na rede pública de esgotos ou em corpos d'água, ou exijam para isso soluções técnicas ou economicamente inviáveis em face da melhor tecnologia disponível (PNRS, 2010). Dentro dessa categoria é necessário salientar os resíduos sólidos urbanos (RSU), esses possuem grande diversidade e várias origens diferentes, advindas das atividades humanas na área urbana. A matéria desprezada pode ser composta por: restos de alimentos em geral, materiais que podem ser reciclados como: plástico, vidro, papel, metais, embalagens, matérias advindas da rede pública, jardins, praças, materiais cerâmicos, couro, trapos, ossos, terra, pedra, material séptico contaminado (originado de serviços de saúde), animais mortos, restos de carros, restos de imóveis, citado os mais importantes (BIDONE e POVINELLI, 1999).

O processo de urbanização e crescente expansão das cidades contribuem significativamente para o aumento dos resíduos sólidos. Os RSU podem variar de cidade para cidade, e essa diferenciação também pode ser notada em cada bairro. Já a quantidade pode ser relacionada com o poder aquisitivo da população, que assim tem condições de consumir, os hábitos e valores de vida, varia também de acordo com a cultura, como o caso dos americanos que podem chegar a gerar dois quilogramas de RSU por habitante ao dia, enquanto os japoneses podem gerar um pouco mais do que um quilograma (GODECKE, et al 2012).

A disposição final correta do resíduo sólido deve ser ambientalmente adequada de modo a não prejudicar o meio ambiente e a população, como por exemplo, os aterros sanitários, que possuem técnicas de engenharia, utilizando a impermeabilização do solo, para que não ocorra vazamento de chorume e a coleta do mesmo, diminuindo dessa forma os impactos ambientais que esses resíduos podem causar, porém ainda tem sido utilizado os lixões e os aterros controlados, que não possuem tanta segurança quanto os aterros sanitários e podem causar contaminações no ambiente. Por esse motivo deve ser feito um planejamento para gestão desses resíduos e sua disposição final adequada.

O estudo gravimétrico dos RSU possibilita a aquisição de informações importantes para direcionar o planejamento com ações visando minimizar a geração dos mesmos. De acordo com GUADAGNIN et al (2001), o reconhecimento e a descrição dos integrantes de cada localidade são importantes para a determinação do método mais adequado, desde a etapa de coleta até a destinação final. Portanto, o estudo gravimétrico 


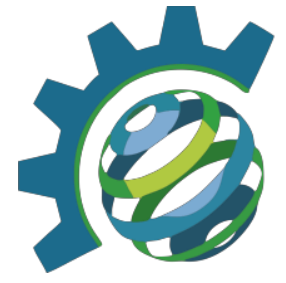

é fundamental para implantação de qualquer técnica ou tecnologia para o tratamento de resíduos.

Os objetivos deste trabalho foram mensurar a geração de RSU na cidade de Bocaiúva- MG de forma quantitativa com o cálculo de produção per capta e peso específico, e de forma qualitativa avaliando a composição gravimétrica.

\section{METODOLOGIA}

\section{1 Área de estudo}

Bocaiúva é um município brasileiro no norte do estado de Minas Gerais. Pertence a mesorregião, localizando-se a norte da capital do estado, distando desta cerca de 369 $\mathrm{km}$, sendo acessada pela rodovia federal BR-135 e estradas secundárias. Ocupa uma área de $3.233 \mathrm{Km}^{2}$, tendo como limites os distritos de Engenheiro Dolabela, Alto belo, Terra Branca e Sentinela. A (Figura 01), apresenta a localização do município de Bocaiuva MG.

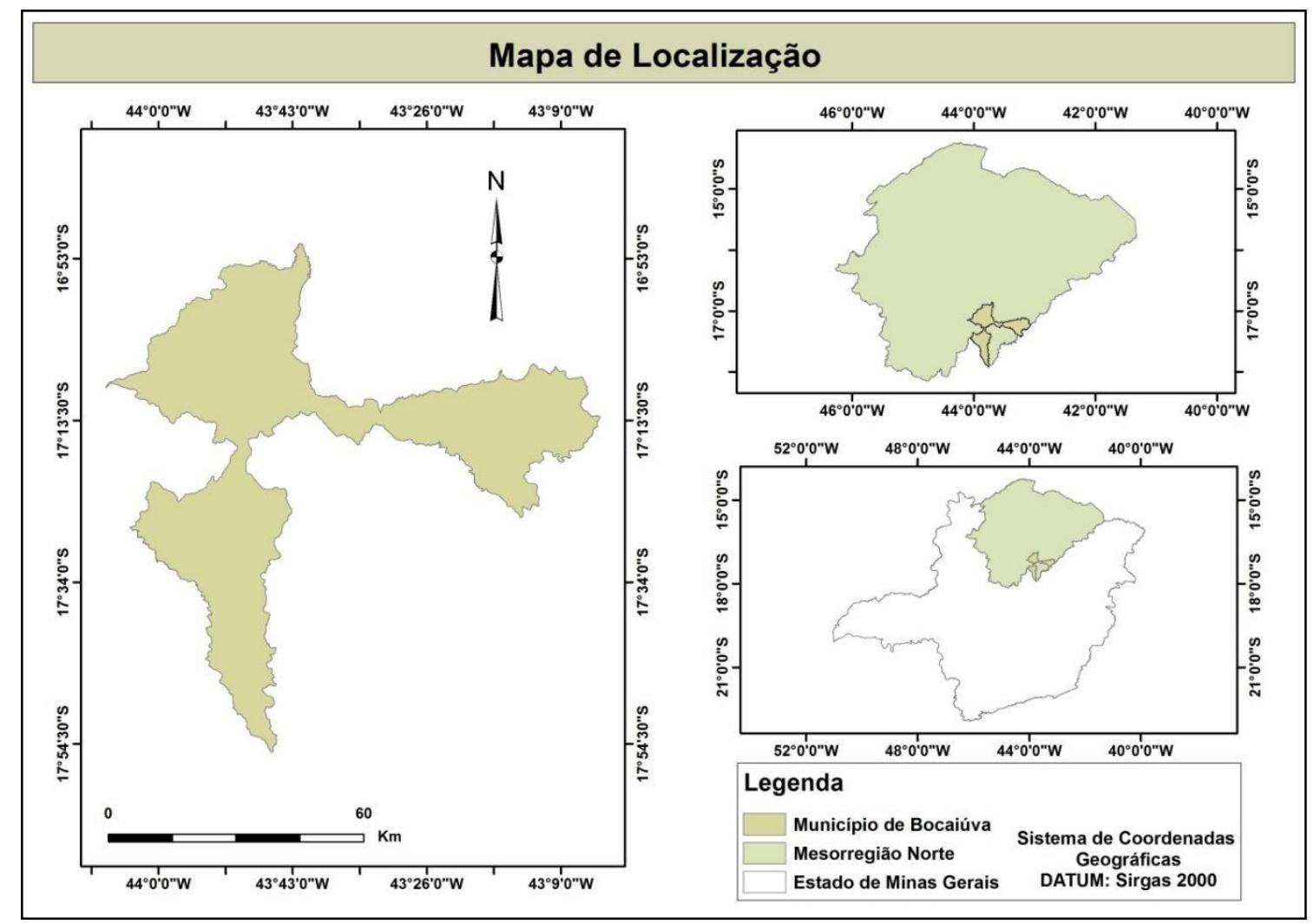

Figura 1. Mapa de Localização 


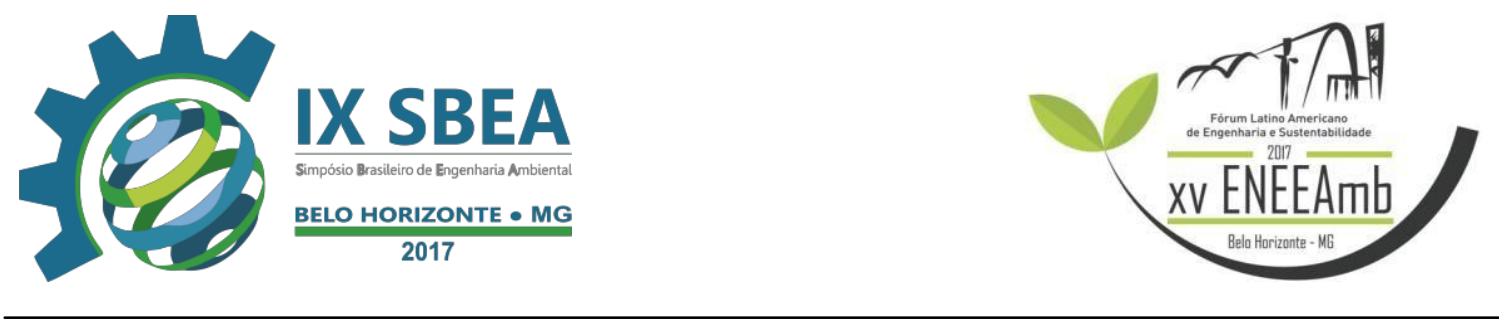

O presente estudo trata-se de uma avaliação da composição gravimétrica dos Resíduos Sólidos Urbanos (RSU) no Município de Bocaiúva-MG, executado por meio de um estudo de caso. Para diagnosticar o modelo de gestão, foi realizada entrevista para levantamentos de dados na Secretária do Meio Ambiente de Bocaiuva, com uma abordagem crítica da situação local dos resíduos coletados na área urbana, até o descarregamento no local ocorreu o questionamento, possibilitando a obtenção de informações necessárias da caracterização dos RSU, explanando os aspectos: destinando o fim do lixo gerado no município, serviço de coleta, transporte, aspectos técnicos e operacionais do aterro sanitário, programas de prevenções de riscos ambientais e programas de gestões.

O município tem contrato com a empresa de coleta Via Solo Engenharia, desde Julho de 2016, para realização da coleta dos RSU, em rotas específicas por três dias da semana segunda, quarta e sexta, realizando rotas regulares nos bairros, através de um caminhão modelo compactador.

Para realizar a composição gravimétrica dos RSU foi necessário fazer uma visita ao local, as amostras foram recolhidas da seguinte forma: uma na parte anterior, uma na posterior e duas no meio, onde o lixo estava sobreposto; primeiramente o RSU, foi pesado em um objeto cilíndrico com volume de 20 litros, depois do resíduo já pesado foi separado nas categorias papel, plástico, vidro, metal, orgânicos e outros, e posteriormente pesado novamente, o procedimento foi repetido quatro vezes, como mostra a Tabela 01.

Os procedimentos para coleta de amostras para análise de composição gravimétrica sugerido pelo Instituto de Pesquisas Tecnológicas (IPT) (1995) e considerando a Associação Brasileira de Normas Técnicas — Norma Brasileira (ABNTNBR) 10007 - Amostragem de resíduos sólidos (ABNT, 2004). Utilizou sacos plásticos para a separação das amostras, em seguida realizou a pesagem dos mesmos, a balança foi tarada com o recipiente vazio, determinando-se a massa total das amostras e o peso específico do recipiente, permitindo, desta maneira, o peso específico médio das amostras. O Peso Específico $(\mathrm{Pe})$ foi calculado conforme segue:

$\mathrm{Pe}=\mathrm{m} / \mathrm{v}(2)$.

Onde: 


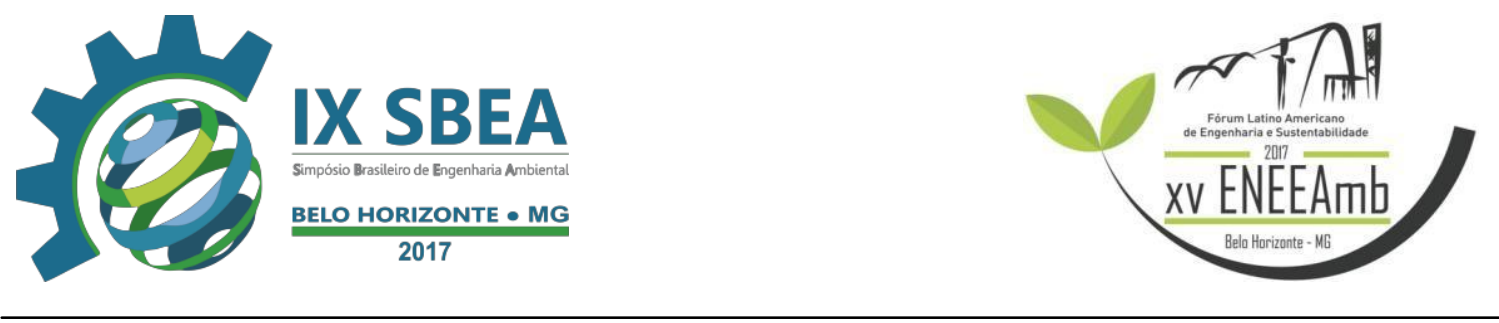

$\mathrm{Pe}=$ Peso específico da amostra (kg.m-3)

$\mathrm{m}=$ Massa da amostra $(\mathrm{kg})$

$\mathrm{v}=$ Volume da amostra $=0,2$ ou $0,1 \mathrm{~m}^{3}$

Após o cálculo do peso específico, os resíduos foram separados por composição

física. Cada elemento (matéria orgânica, papel e papelão, metais, plástico, vidros, etc.)

foi pesado separadamente calculando-se o percentual em relação ao total.

Tabela 01. Composição gravimétrica dos RSU.

\begin{tabular}{|c|c|c|c|c|c|c|c|}
\hline $\begin{array}{l}\text { PROCEDIMENT } \\
\text { O }\end{array}$ & $\begin{array}{l}\text { PESO } \\
\text { TOTAL DO } \\
\text { RESÍDUO } \\
\text { (KG) }\end{array}$ & $\begin{array}{l}\text { VIDR } \\
\text { O } \\
\text { (KG) }\end{array}$ & $\begin{array}{l}\text { PAPE } \\
\text { L } \\
\text { (KG) }\end{array}$ & $\begin{array}{l}\text { PLÁSTIC } \\
\text { O } \\
\text { (KG) }\end{array}$ & $\begin{array}{l}\text { METAL } \\
\text { (KG) }\end{array}$ & $\begin{array}{l}\text { ORGÂNIC } \\
\text { O } \\
\text { (KG) }\end{array}$ & $\begin{array}{l}\text { OUTRO } \\
\text { S } \\
\text { (KG) }\end{array}$ \\
\hline 01 & 2,02 & 0,02 & 0,68 & 0,56 & 0,02 & 0,74 & - \\
\hline 02 & 4,74 & - & 0,66 & 1,46 & - & 2,62 & - \\
\hline 03 & 3,36 & - & 1,26 & 1,12 & - & 0,98 & - \\
\hline 04 & 2,14 & - & 0,74 & 0,76 & 0,12 & 0,52 & - \\
\hline
\end{tabular}

Para o cálculo da população futura para os próximos 25 anos, adotou-se o método aritmético utilizando a fórmula.

Pf: Po+R(Tf-To)

R: Puc-Ppc / Auc- Apc

Onde:

Pf: População futura

Po: População Inicial

Tf: Tempo final (ano)

To: Tempo Inicial (ano)

Puc: População do último censo

Ppc: População do penúltimo censo

Auc: Ano do último censo

Apc: Ano do Penúltimo censo 


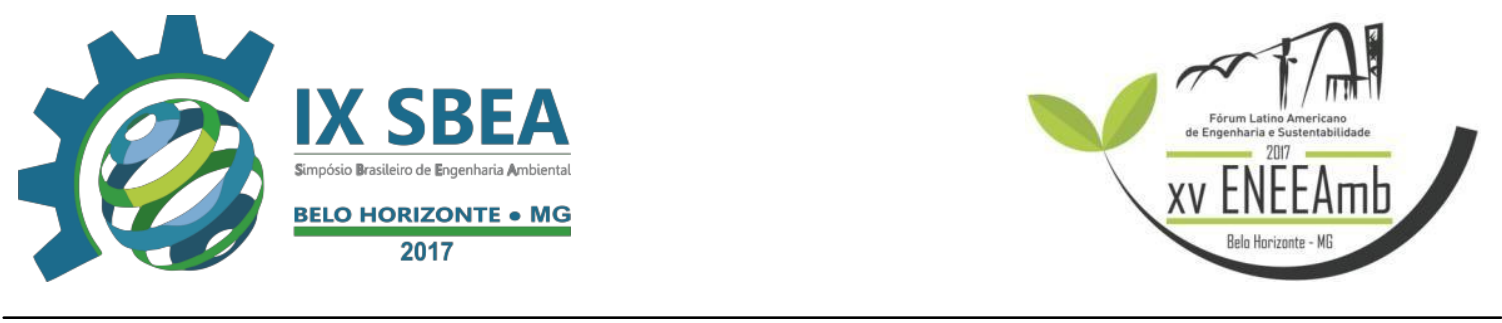

\section{RESULTADOS E DISCUSSÃO}

O serviço de limpeza pública do município de Bocaiuva atualmente é terceirizado e a responsável pelo acompanhamento e verificação dos serviços prestados pela empresa privado é a Secretaria Municipal de Meio Ambiente.

A empresa dispõe diariamente de quatro caminhões compactadores com capacidade de $08 \mathrm{~m}^{3}$, são coletadas aproximadamente 27,7199 toneladas/dia de resíduos sólidos no município que são dispostos no aterro sanitário.

\section{Composição Gravimétrica dos Resíduos Sólidos}

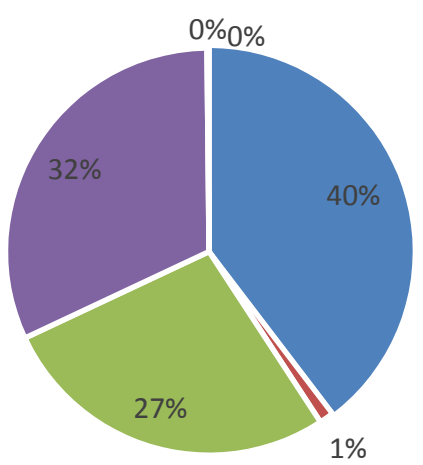

Figura 6. Fonte: Próprio autor

Tabela 02. Composição gravimétrica dos RSU.

\begin{tabular}{ccccc}
\hline \multicolumn{2}{c}{ COMPOSIÇÃO GRAVIMÉTRICA } & & \multicolumn{2}{c}{$\begin{array}{c}\text { Massa } \\
\text { Diária }\end{array}$} \\
\hline ORGÂNICO & Gramas & $\%$ & Tonelada & Tonsa Mensal \\
METAL & 1215 & 39,64 & 10988,52 & 329655,46 \\
PAPEL & 35 & 1,14 & 316,54 & 9496,25 \\
PLÁSTICO & 835 & 27,24 & 7551,78 & 226553,34 \\
VIDROS & 975 & 31,81 & 8817,94 & 264538,34 \\
OUTROS & 5 & 0,16 & 45,22 & 1356,61 \\
TOTAL & 0 & 0,00 & 0,00 & 0,00 \\
\hline
\end{tabular}

A Composição Gravimétrica de Resíduos Sólidos Urbanos apresenta um processo por meio do qual se obtém uma parcela significativa da geração de resíduos sólidos, a fim de caracterizá-la qualitativa e quantitativamente. Após coletas de dados foi realizada a caracterização gravimétrica dos Resíduos Sólidos da Cidade de 


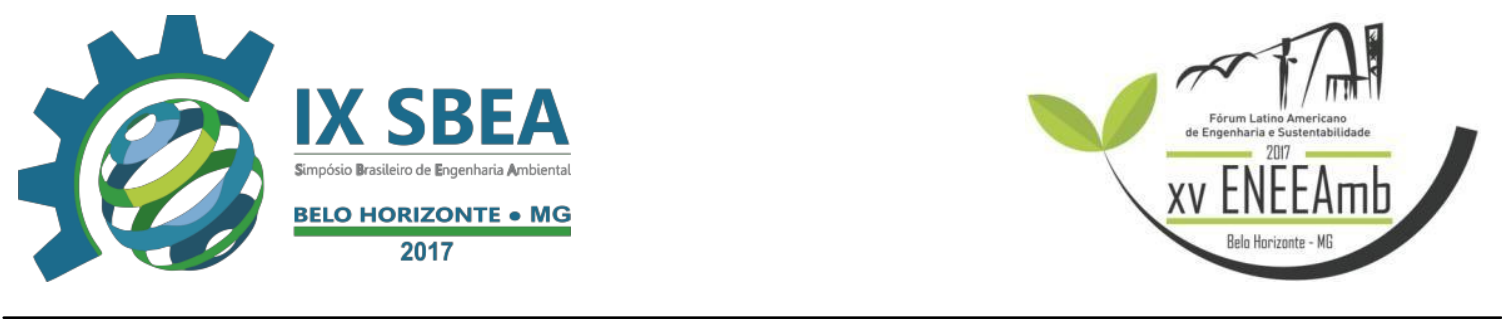

Bocaiuva- MG, apresentando maior taxa de material orgânico obtendo $40 \%$ dos $\mathrm{RS}$ coletados, seguido materiais recicláveis que somam 60\% dos RS, ex: papel, plástico, metal e vidro. De acordo com os resultados obtidos o percentual de RS orgânico é bem elevado, devido a coleta ser feita em residências domésticas levando em consideração o alto nível de consumação da população, e a falta de conscientização em relação ao desperdício de alimentos. Devido ao desenvolvimento econômico e ao crescimento urbano na cidade é gasto muito papel e plástico, por ser um material mais utilizado para armazenar resíduos domiciliares e comerciais, os metais não atingiu uma parcela significativa nas amostras coletadas.

Tabela 03. Resultados do cálculo para a população dos próximos 25 anos.

\begin{tabular}{|c|c|c|}
\hline Ano & População Total (hab) & População Urbana (hab) \\
\hline 2017 & 49348 & 39508 \\
\hline 2018 & 49732 & 39923 \\
\hline 2019 & 50117 & 40339 \\
\hline 2020 & 50502 & 40754 \\
\hline 2021 & 50887 & 41169 \\
\hline 2022 & 51272 & 41585 \\
\hline 2023 & 51656 & 42000 \\
\hline 2024 & 52041 & 42416 \\
\hline 2025 & 52426 & 42831 \\
\hline 2026 & 52811 & 43246 \\
\hline 2027 & 53196 & 43662 \\
\hline 2028 & 53580 & 44077 \\
\hline 2029 & 53965 & 44493 \\
\hline 2030 & 54350 & 44908 \\
\hline 2031 & 54735 & 45323 \\
\hline 2032 & 55120 & 45739 \\
\hline 2033 & 55504 & 46154 \\
\hline 2034 & 55889 & 46570 \\
\hline
\end{tabular}



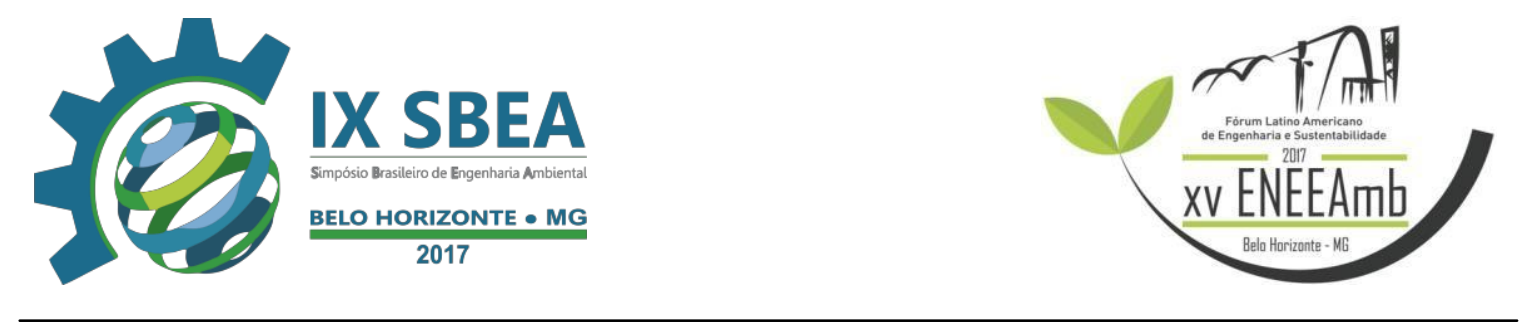

$\begin{array}{lll}\mathbf{2 0 3 5} & 56274 & 46985 \\ \mathbf{2 0 3 6} & 56659 & 47400 \\ \mathbf{2 0 3 7} & 57044 & 47816 \\ \mathbf{2 0 3 8} & 57428 & 48231 \\ \mathbf{2 0 3 9} & 57813 & 48647 \\ \mathbf{2 0 4 0} & 58198 & 49062 \\ \mathbf{2 0 4 1} & 58583 & 49477 \\ \mathbf{2 0 4 2} & 58968 & 49893\end{array}$

A tabela 03 acima demonstra a estimativa do crescimento da população nos próximos 25 anos, para basear o cálculo do dimensionamento do aterro, tendo em vista que a vida útil do mesmo é de 35 anos.

Tabela 04. Cálculo da população total e urbana de forma aritmética.

Município de Bocaiuva-MG

\begin{tabular}{|c|c|c|c|c|c|c|}
\hline Período & $\begin{array}{l}\text { População } \\
\text { Urbana }\end{array}$ & $\begin{array}{l}\text { Geração per capta }(\mathrm{kg} / \\
\text { hab.dia) }\end{array}$ & $\begin{array}{l}\text { Geração } \\
\text { RSU } \\
\text { diária- } \\
\text { Ton }\end{array}$ & $\begin{array}{l}\text { Geração de } \\
\text { RSU anual- } \\
\text { Ton }\end{array}$ & $\begin{array}{l}\text { Volume } \\
\text { RSU } \\
\text { diário- } \\
\mathrm{m}^{3}\end{array}$ & $\begin{array}{l}\text { Volume } \\
\text { RSU anual- } \\
\mathrm{m}^{3}\end{array}$ \\
\hline 2017 & 39508 & 0,7016 & 27,7199 & 10117,7488 & 176,0 & 64239,7 \\
\hline 2018 & 39923 & 0,7086 & 28,2914 & 10326,3719 & 179,6 & 65564,3 \\
\hline 2019 & 40339 & 0,7157 & 28,8717 & 10538,1558 & 183,3 & 66908,9 \\
\hline 2020 & 40754 & 0,7229 & 29,4607 & 10753,1427 & 187,1 & 68273,9 \\
\hline 2021 & 41169 & 0,7301 & 30,0586 & 10971,3755 & 190,8 & 69659,5 \\
\hline 2022 & 41585 & 0,7374 & 30,6655 & 11192,8976 & 194,7 & 71066,0 \\
\hline 2023 & 42000 & 0,7448 & 31,2815 & 11417,7531 & 198,6 & 72493,7 \\
\hline 2024 & 42416 & 0,7522 & 31,9068 & 11645,9863 & 202,6 & 73942,8 \\
\hline 2025 & 42831 & 0,7598 & 32,5415 & 11877,6425 & 206,6 & 75413,6 \\
\hline 2026 & 43246 & 0,7674 & 33,1857 & 12112,7672 & 210,7 & 76906,5 \\
\hline 2027 & 43662 & 0,7750 & 33,8395 & 12351,4066 & 214,9 & 78421,6 \\
\hline 2028 & 44077 & 0,7828 & 34,5030 & 12593,6075 & 219,1 & 79959,4 \\
\hline 2029 & 44493 & 0,7906 & 35,1765 & 12839,4173 & 223,3 & 81520,1 \\
\hline 2030 & 44908 & 0,7985 & 35,8600 & 13088,8840 & 227,7 & 83104,0 \\
\hline 2031 & 45323 & 0,8065 & 36,5536 & 13342,0560 & 232,1 & 84711,5 \\
\hline
\end{tabular}




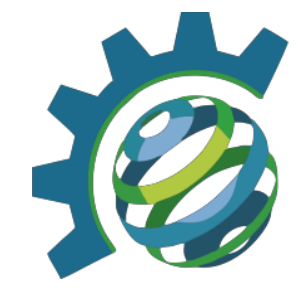

\begin{tabular}{lllllll}
\hline $\mathbf{2 0 3 2}$ & 45739 & & & & & \\
\cline { 3 - 6 } $\mathbf{2 0 3 3}$ & 46154 & 0,8146 & 37,2575 & 13598,9826 & 236,6 & 86342,7 \\
$\mathbf{2 0 3 4}$ & 46570 & 0,8227 & 37,9718 & 13859,7135 & 241,1 & 87998,2 \\
$\mathbf{2 0 3 5}$ & 46985 & 0,8309 & 38,6967 & 14124,2992 & 245,7 & 89678,1 \\
$\mathbf{2 0 3 6}$ & 47400 & 0,8393 & 39,4323 & 14392,7905 & 250,4 & 91382,8 \\
$\mathbf{2 0 3 7}$ & 47816 & 0,8476 & 40,1787 & 14665,2393 & 255,1 & 93112,6 \\
$\mathbf{2 0 3 8}$ & 48231 & 0,8561 & 40,9362 & 14941,6978 & 259,9 & 94867,9 \\
$\mathbf{2 0 3 9}$ & 48647 & 0,8647 & 41,7047 & 15222,2189 & 264,8 & 96649,0 \\
$\mathbf{2 0 4 0}$ & 49062 & 0,8733 & 42,4845 & 15506,8562 & 269,7 & 98456,2 \\
$\mathbf{2 0 4 1}$ & 49477 & 0,8821 & 43,2758 & 15795,6641 & 274,8 & 100289,9 \\
$\mathbf{2 0 4 2}$ & 49893 & 0,8909 & 44,0786 & 16088,6975 & 279,9 & 102150,5 \\
\hline Volume acumulado & 0,8998 & 44,8932 & 16386,0119 & 285,0 & 104038,2 \\
\hline
\end{tabular}

A tabela 04 acima mostra o crescimento da população urbana até 2042 considerando um aumento na geração per capta ao ano. Ao fim dos 25 anos o volume total de resíduos seria aproximadamente 2.157.151,6 $\mathrm{m}^{3}$, considerando um grau de compactação de $1 / 4$ o resíduo compactado passaria a ter volume de $539.287,9 \mathrm{~m}^{3}$, portanto para dimensionar um aterro deveria ser considerado esse volume compactado após 25 anos, porem o seu dimensionamento também deve levar em consideração a espessura das camadas de terra que é necessário para evitar o mau cheiro e a proliferação de bactérias patógenas.

\section{CONCLUSÕES/RECOMENDAÇÕES}

A composição gravimétrica dos resíduos coletados na cidade de Bocaiuva obteve um porcentual de matéria orgânica de $40 \%$ e quase $60 \%$ de materiais recicláveis o que apresenta a importância de estudar alternativas para a implementação de um sistema de compostagem de resíduos para o município, uma vez que não é feita a separação entre os resíduos recicláveis e a matéria orgânica dos RSU, o volume de material depositado no aterro sanitário aumenta consideravelmente, reduzindo a vida útil do mesmo. A separação do material reciclável dos resíduos reverteria em ganhos financeiros para a população do município, uma vez que aumentaria sua arrecadação com a comercialização dos resíduos. 


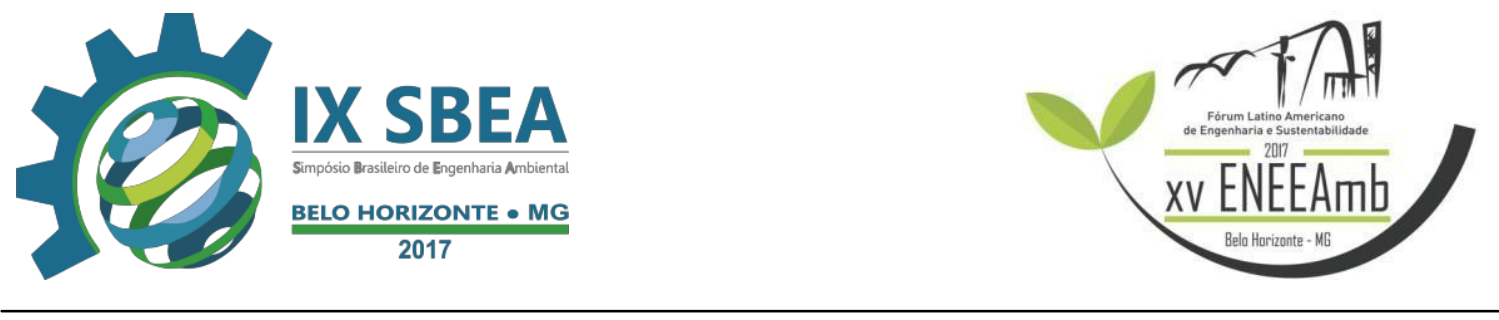

É de grande importância que se elabore um Plano de Gerenciamento Integrado de Resíduos Sólidos Urbanos que melhore desde a coleta seletiva, alternativas de reciclagem e uma disposição final adequada em aterro sanitário, e ainda utilizando ferramentas chaves como a Educação Ambiental, conscientização da população capaz de sensibilizar a mesma para condutas e comportamentos que contribuam para o funcionamento adequado do sistema implantado, tendo sempre em vista o correto manejo ambiental.

\section{REFERÊNCIAS BIBLIOGRÁFICAS}

BIDONE, F. R. A; POVINELLI, J. Conceitos básicos de resíduos sólidos. São Carlos: EESC/USP, 1999. 120 p.

GODECKE, M. V.; NAIME, R. H.; FIGUEIREDO, J. A. S. O Consumismo e a Geração de Resíduos Sólidos Urbanos no Brasil. Revista Eletrônica em Gestão, Educação e Tecnologia Ambiental - Universidade Federal de Mato Grosso do Sul UFMS, 2012.

ASSOCIAÇÃO BRASILEIRA DE NORMAS TÉCNICAS (ABNT). (2004) NBR 10007: Amostragem de resíduos. Rio de Janeiro: ABNT. 